\title{
Lactobacillus plantarum (VR1) isolated from an Ayurvedic medicine (Kutajarista) ameliorates in vitro cellular damage caused by Aeromonas veronii
}

Himanshu Kumar ${ }^{1}$, Ashraf Y Rangrez ${ }^{2}$, Kannayakanahalli M Dayananda ${ }^{3}$, Ashwini N Atre ${ }^{1}$, Milind S Patole ${ }^{1}$ and Yogesh S Shouche ${ }^{1,4^{*}}$

\begin{abstract}
Background: Lactobacillus plantarum is considered as a safe and effective probiotic microorganism. Among various sources of isolation, traditionally fermented foods are considered to be rich in Lactobacillus spp., which can be exploited for their probiotic attribute. Antibacterial property of L. plantarum has been demonstrated against various enteric pathogens in both in vitro and in vivo systems. This study was aimed at characterizing L. plantarum isolated from Kutajarista, an ayurvedic fermented biomedicine, and assessing its antagonistic property against a common enteropathogen Aeromonas veronii.
\end{abstract}

Results: We report the isolation of L. plantarum (VR1) from Kutajarista, and efficacy of its cell free supernatant (CFS) in amelioration of cytotoxicity caused by Aeromonas veronii. On the part of probiotic attributes, VR1 was tolerant to $\mathrm{pH} 2,0.3 \%$ bile salts and simulated gastric juice. Additionally, VR1 also exhibited adhesive property to human intestinal HT-29 cell line. Furthermore, CFS of VR1 was antibacterial to enteric pathogens like Pseudomonas aeruginosa, Staphylococcus aureus, Escherichia coli, Aeromonas veronii and clinical isolates of P. aeruginosa and E. coli. Detailed study regarding the effect of VR1 CFS on A. veronii cytotoxicity showed a significant decrease in vacuole formation and detrimental cellular changes in Vero cells. On the other hand, A. veronii CFS caused disruption of tight junction proteins ZO-1 and actin in MDCK cell line, which was prevented by pre-incubation with CFS of VR1.

Conclusions: This is the first study to report isolation of L. plantarum (VR1) from Kutajarista and characterisation for its probiotic attributes. Our study demonstrates the antagonistic property of VR1 to A. veronii and effect of VR1 CFS in reduction of cellular damage caused by A. veronii in both Vero and MDCK cell lines.

\section{Background}

Lactic acid bacteria is now widely used as probiont for its multifactorial benefits to humans as well as to organisms like fish, poultry and other live stock. In addition to various sources of isolation [1-3], several recent studies have described the isolation and characterisation of probiotic microorganisms from traditionally fermented sources like Dongchimi, Kimchi, Meju, and Doenjang [4], and Kallappam batter, Koozh and Mor Kuzhambu [5]. Likewise, traditional Ayurvedic medicines might

\footnotetext{
* Correspondence: yogesh@nccs.res.in

'Molecular Biology Unit, National Centre for Cell Science, Ganeshkhind, Pune, Maharashtra, India

Full list of author information is available at the end of the article
}

serve as a source and a reservoir of potential probiotic microbes. Nevertheless, there are very little efforts made in exploration of probionts from ayurvedic fermented sources. To the best of our knowledge, Kanjika is the only Ayurvedic source explored in detail for the isolation and in vitro characterisation of Lactobacillus spp. for probiotic attributes [6]. In this study, Kutajarista is used as a source for the isolation of potential probiotic isolates. Kutajarista is a well known polyherbal Ayurvedic formulation prepared traditionally by fermentation of the decoction of Holarrhena antidysentrica as the main constituent [7]. It is being prescribed for a number of chronic diseases like amoebic dysentery, piles, 
intestinal parasites infestation and other disorders like fever, indigestion, and malabsorption syndrome [8].

There are growing number of studies that show the ability of Lactobacillus spp. to antagonize various pathogens, like enterohemorrhagic E. coli $[9,10]$, Helicobacter pylori [11], Salmonella typhimurium [12], Shigella dysenteriae [13], using in vitro and in vivo systems. Probiotic microorganisms like Lactobacillus spp. exert beneficial effects on epithelial cells by secreting bioactive and extracellular proteins. Moreover, the active fraction has been isolated and tested for its activity as immunomodulators and inhibitors for pathogenic microorganisms [14,15]. Some recent reports also suggest the restoration of barrier function in epithelial cells by probiotic treatment due to the strengthening of tight junctions $[10,16]$. Gene expression profiling of tight junction proteins demonstrated the effect of L. plantarum MB452 in strengthening of tight junction associated proteins in Caco2 cell line [17]. Additionally, immunolocalization studies on tight junction proteins like $\mathrm{ZO}-1$, claudin and F-actin demonstrate preventive role of $L$. sobrius in enterotoxigenic effect of $E$. coli K88 [18].

Among the species of Aeromonas, A. hydrophila, A. salmonicida and $A$. veronii are considered as emerging human pathogens and have a potent role in various gastrointestinal disorders. Several clinical studies highlight the outbreak of Aeromonas spp. infection in diarrhoea [19-21]. Aeromonas spp. harbours at various ecological niche, making the transmission of this pathogen more susceptible to humans [22]. A. veronii (MTCC 3249), bacterial strain that is used in this study was first reported from a mosquito midgut and subsequently reported from drinking water supplies and other sources [23-25], possess multiple virulence attributes like haemolytic activity, plasmids, quorum sensing and type four secretion system. These virulent properties can be implicated in its role for toxin production and transfer of antibiotic resistance genes across and within the genera [26-29]. In addition to previously established virulence traits, $A$. veronii was found to be coding for aerolysin and type three secretion systems.

In the current study, we isolated and characterised potential probiotic microorganisms from an Ayurvedic formulation, Kutajarista. We identified one of our twelve isolates, VR1, homologous to L. plantarum as a promising candidate exhibiting tolerance to low $\mathrm{pH}$, bile salts and simulated gastric juice conditions. Accompanying studies demonstrated that VR1 is adherent to human derived HT-29 cells and antagonises the growth of commonly known pathogens like $S$. aureus, $P$. aeruginosa and particularly A. veronii. We further demonstrated that vacuole formation, epithelial damage and cytotoxicity caused by $A$. veronii was reduced or ameliorated by VR1.

\section{Results}

VR1 isolated from Kutajarista exhibited strong probiotic attributes

Twelve isolates obtained after enrichment of Kutajarista in MRS broth were identified on the basis of $16 \mathrm{~S}$ rRNA gene sequencing. One of the isolates showed maximum homology with L. plantarum based on $16 \mathrm{~S}$ rRNA gene sequence [GenBank: HQ328838]. Its phylogenetic affiliation was deduced by comparing the homologous $16 \mathrm{~S}$ rRNA gene sequences from NCBI and the phylogenetic tree is shown in additional file 1, Fig S1.

Acid, bile and gastric juice tolerance is considered to be the preliminary characteristics of any strain to claim its probiotic potential $[2,30]$. VR1 showed tolerance to low $\mathrm{pH}(\mathrm{pH} 2.0)$, bile salt concentration of $0.3 \%$ and simulated gastric juice. There was a little increase of 0.3 $\log (\mathrm{CFU} / \mathrm{ml})$ during the course of incubation for $3 \mathrm{~h}$, which further suggested that it can tolerate and remain viable at acidic $\mathrm{pH} 2.0$ (Figure 1). In $0.3 \%$ bile, there was increase of $0.5 \mathrm{Log}(\mathrm{CFU} / \mathrm{ml})$ after $3 \mathrm{~h}$ of incubation and in simulated gastric juice tolerance test, a decrease of $0.4 \log (\mathrm{CFU} / \mathrm{ml})$ on growth was observed. L. plantarum is known to be adherent to intestinal cell lines like Caco2 and HT-29. This study showed that VR1 was adherent to HT-29 cell line with the adhesion ratio of $6.8 \pm 0.2 \%$, which was in concordance with the earlier studies [31].

CFS of VR1 antagonised the growth of enteric pathogens Antagonistic activity of VR1 culture supernatant was examined using well-diffusion test against $S$. aureus

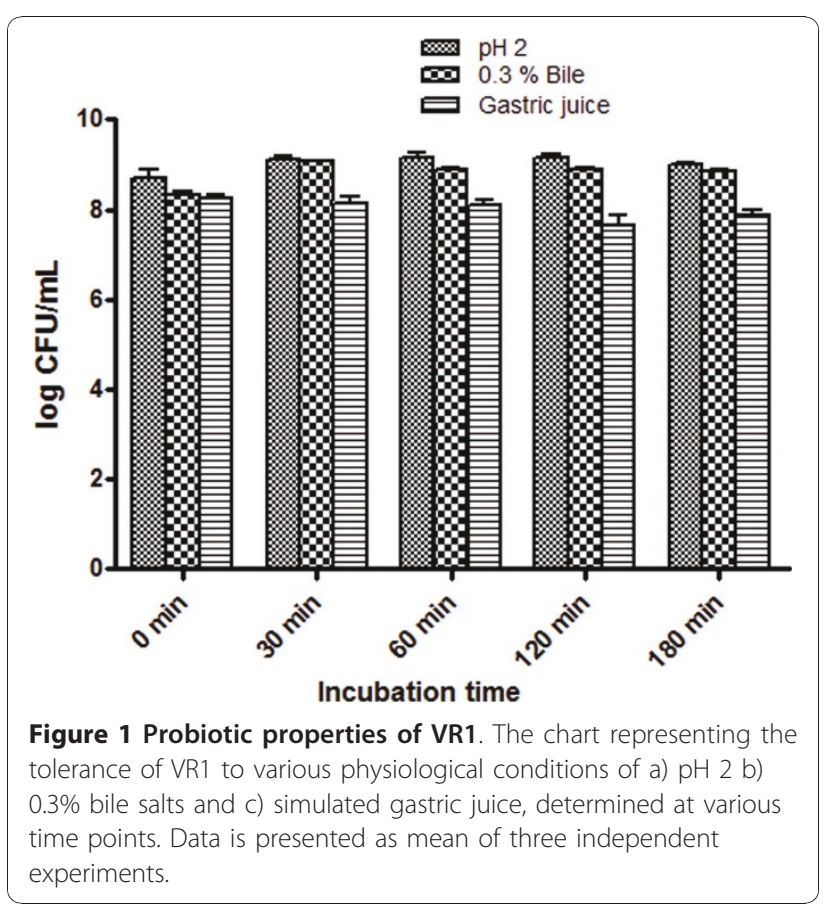


(ATCC 6538P), S. lutea (ATCC 9341), A. veronii (MTCC 3249), E. coli (ATCC 8739), P. aeruginosa (ATCC 27853), S. epidermidis (ATCC 12228), and clinical isolates of $P$. aeruginosa (DMH 1), and E. coli (DMH 9). VR1 showed antimicrobial activity against all the tested microorganisms, with strong antibacterial activity against $A$. veronii with $22 \mathrm{~mm}$ inhibitory zone (Table 1 ).

\section{Vacuole formation by $A$. veronii on Vero cells were moderated by VR1 CFS}

Sensitivity of Vero cells for Aeromonas cytotoxicity has been well documented [32-34]. Vero cells were treated with CFS of $A$. veronii and VR1, in 1:10 ratio in DMEM. Figure 2 revealed the formation of perinuclear vacuoles in more than $50 \%$ of cells and cell detachment was observed after five hours of incubation with $A$. veronii CFS; however, pre-incubation with VR1 supernatant for $6 \mathrm{~h}$ reduced the vacuole formation and cell detachment.

Time lapse microscopy revealed delayed cytotoxic effects of $A$. veronii on Vero cells pre-incubated with VR1

Time lapse microscopic images were taken at various time intervals for $10 \mathrm{~h}$ (Figure 3 ). Treatment with $A$. veronii supernatant in 1:10 ratio to media started showing acute cytopathic effect with cell detachment from the surface, after $6 \mathrm{~h}$ of incubation. Alteration in Vero cells was followed by a change from normal spindle shaped to round swollen morphology with an extensively altered cytoplasm and gradual destruction of the monolayer. However, these cytopathic effects were delayed by $2 \mathrm{~h}$, where $A$. veronii supernatant was coincubated with VR1 supernatant. Vero cells pre-treated for $6 \mathrm{~h}$ with VR1 supernatant showed marked reduction in the cytotoxicity caused by $A$. veronii, and only few cells were detached even after $10 \mathrm{~h}$ of incubation.

\section{VR1 prevented disruption of ZO-1 and F-actin} caused by $A$. veronii

Immunofluorescence for tight junction protein $\mathrm{ZO}-1$, revealed continuous and circumferential ZO-1

Table 1 Antibacterial activity of VR1 against various pathogens

\begin{tabular}{ll}
\hline Test Organism & Zone of Inhibition $\mathbf{( m m})^{\mathbf{1 , 2}}$ \\
\hline Staphylococcus aureus (ATCC6538P) & 18 \\
Sarcina lutea (ATCC 9341) & 17 \\
Escherichia coli (ATCC 8739) & 20 \\
Pseudomonas aeruginosa (ATCC27853) & 18 \\
Staphylococcus epidermidis (ATCC12228) & 16 \\
Pseudomonas aeruginosa (DMH 1) & 16 \\
Escherichia coli (DMH 9) & 16 \\
Aeromonas veronii(MTCC 3249) & 22 \\
\hline
\end{tabular}

${ }^{1}$ Diameter of the well $7 \mathrm{~mm} .{ }^{2}$ Values shown represent the mean of three replicates distribution in MDCK cells treated with VR1 CFS (Figure 4a3) similar to control cells (Figure 4a1). However, fragmented, diffused and punctated pattern of ZO-1 distribution was observed in case of cells treated with $A$. veronii supernatant (Figure 4a2). Pre-incubation of MDCK cells with VR1 for $6 \mathrm{~h}$ prior to A. veronii infection prevented these changes and showed clear delineation of cellular borders in a belt like manner (Figure 4a5). Treatment with $A$. veronii supernatant led to disorganisation of actin filaments and nuclear condensation was also observed (Figure 4b2 \&4c2). However, pre-incubation of cells with VR1 supernatant maintained the cellular morphology comparable to control cells. In both the treatments i.e. VR1 CFS, and A. veronii CFS treatment on cells that were pre-incubated with CFS of VR1, actin filaments were present in high density at the apical perijunctional regions, encircling the cells in a belt like manner (Figure 4b3 \&4b5). However, co-incubation of $A$. veronii and VR1 supernatant (Figure $4 \mathrm{a} 4$ to $4 \mathrm{~d} 4$ ) led to the loss of membrane architecture with loss of fluorescence of ZO-1 and actin, as observed in $A$. veronii treatment group.

\section{CFS of VR1 significantly lowered cytotoxicity}

induced by $A$. veronii

The cytotoxic effect of $A$. veronii CFS was confirmed by MTT assay, which essentially checks cell viability (Figure 5). Cell viability was reduced to $60 \%$ in Vero cells treated with $A$. veronii supernatant for $10 \mathrm{~h}$. Interestingly, Vero cells when pre-incubated with VR1 CFS for $6 \mathrm{~h}$ followed by $10 \mathrm{~h}$ of treatment with $A$. veronii CFS showed no loss of cell viability. Similarly, VR1 CFS treatment did not show any detrimental effects on cells with no loss in cell viability. However, co-incubation of VR1 and $A$. veronii supernatant was not effective in preventing cytotoxicity caused by $A$. veronii.

\section{Discussion}

Kutajarista is an Ayurvedic formulation prescribed for the treatment of dysentery, piles etc. Initial characterisation of bacterial diversity of Kutajarista by the $16 \mathrm{~S}$ rRNA gene clone library [GenBank: HQ875575HQ875614] provided evidence about the richness of Lactobacillus spp. in the preparation of ayurvedic medicine. Therefore, the current study was aimed at characterization of probiotic and antibacterial properties of L. plantarum VR1 isolated from Kutajarista, against a known cytotoxic and virulent strain, A. veronii. Previously, it has been reported that $L$. delbrueckii, L. lactis and $L$. mesenteroides can prevent cellular damage caused by $A$. salmonicida, a fish pathogen $[35,36]$. Here we report that VR1 possess strong probiotic properties and abrogated the cytotoxicity of $A$. veronii MTCC 3249, an isolate from mosquito midgut. To the best of our 


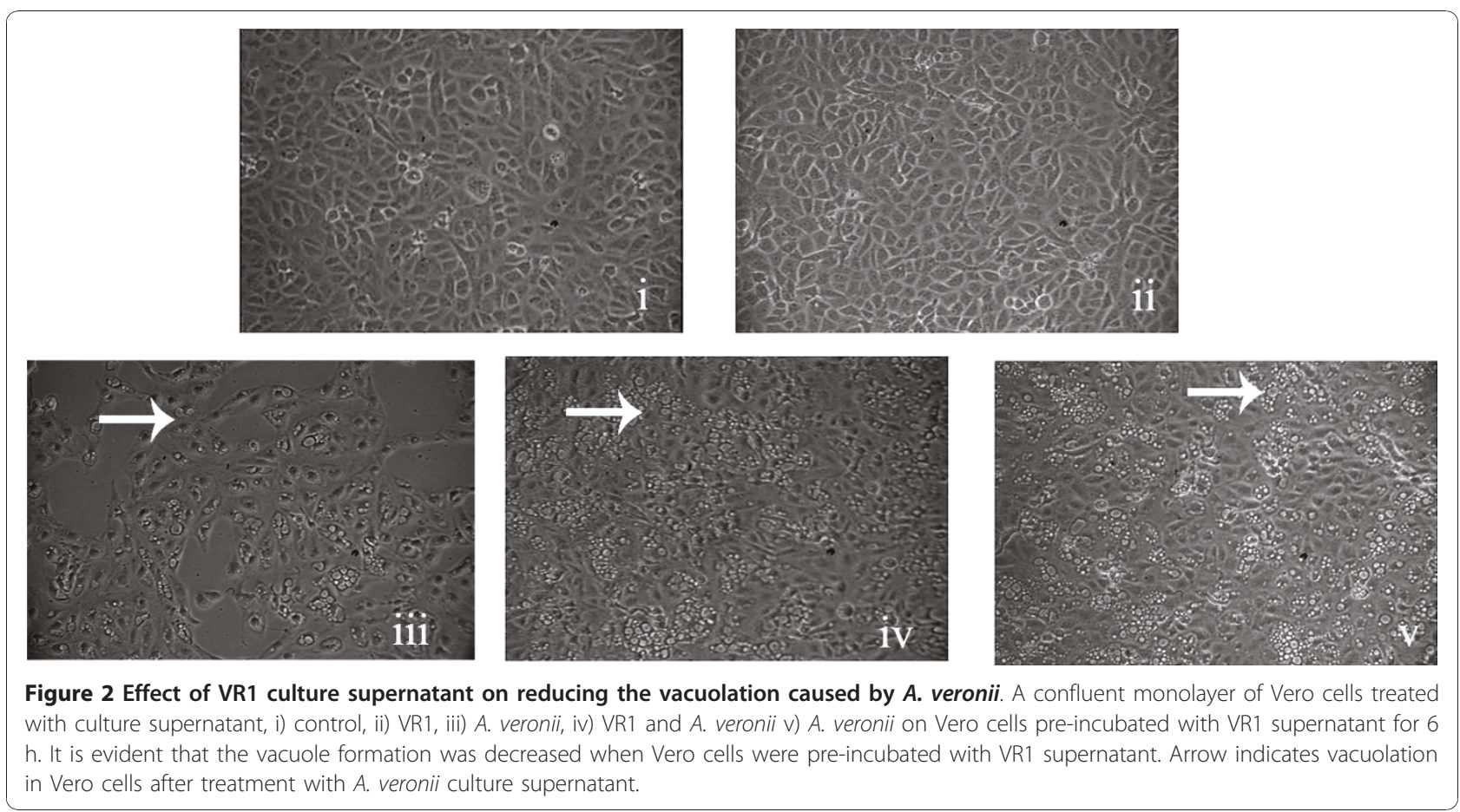

knowledge this is the first report of the preventive role of CFS from VR1 in cellular and epithelial damage caused by $A$. veronii.

Traditionally fermented products are rich source of Lactobacilli, which can be exploited for their probiotic potential. Indian fermented foods like Kallappam, koozh and Mor Kuzhambu were reported as a source of potential probiotic Lactobacillus spp. and which is useful as biopreservative [5]. Ayurveda is traditionally practised medicinal science for many centuries and medicines are prepared from herbs. However, very little efforts have been made in utilizing these preparations as a source of probionts. There is only major study which reported the isolation and charactarisation of seventeen Lactobacillus spp. from Kanjika, an Ayurvedic formulation, for probiotic attributes [6]. In the present study, we used Kutajarista, an Ayurvedic herbal decoction, for isolation of potential probiont. VR1 showed highest homology to $L$. plantarum and exhibited probiotic characteristics such as tolerance to acidic $\mathrm{pH}$, bile salts and simulated gastric juice. VR1 also showed adherence to intestinal cell line HT-29, which is one of the essential prerequisites for a probiotic microorganism. All these features indicate this strain of L. plantarum as a potential probiont. A recent report by Anderson et al. [37] suggests that L. plantarum has better probiotic characteristics and it also reduces enteropathogenic effect of $E$. coli as compared to commercial strains like L. rhamnosus. Moreover, $L$. plantarum has been reported to inhibit pathogens in in vitro and in vivo systems $[9,13]$. On the same lines, $L$. plantarum isolated from Kutajarista showed inhibition of the tested type strains and clinical isolates of $P$. aeruginosa and E. coli. Interestingly VR1 also prevented the growth of $A$. veronii, for which virulent attributes have already been established [26-28].

The pathogenicity of genus Aeromonas is multifactorial and is attributed to factors such as; cytotoxin, aerolysin, hemolysin, adhesins and secretory systems. Apart from other virulence factors which may contribute to the pathogenesis of $A$. veronii, here we report the presence of type three secretion system and aerolysin (additional file 2, Fig S2), putatively involved in secretion of virulence factors to the host cell and haemolytic activity respectively. Our previous studies have also demonstrated that A. veronii MTCC 3249 is multi-drug resistant, and harbours three uncharacterised plasmids and one of the plasmids codes for functional type four secretion system $[26,28,29]$.

After establishing the fact that $A$. veronii was cytotoxic to mammalian cells and harbours many virulence factors, our next goal was to observe the protective or preventive role of VR1 in $A$. veronii infection. We used CFS of VR1 to examine its efficacy in amelioration of cytotoxicity caused by $A$. veronii supernatant. We observed high level of vacuole formation as an indication of cytotoxicity and morphological changes in Vero cells. Earlier, in an enterohaemorrhagic E. coli infection model, it was shown that pre-incubation with L. plantarum abolished the cytotoxicity caused by enteropathogenic strain [10]. To test whether VR1 had 

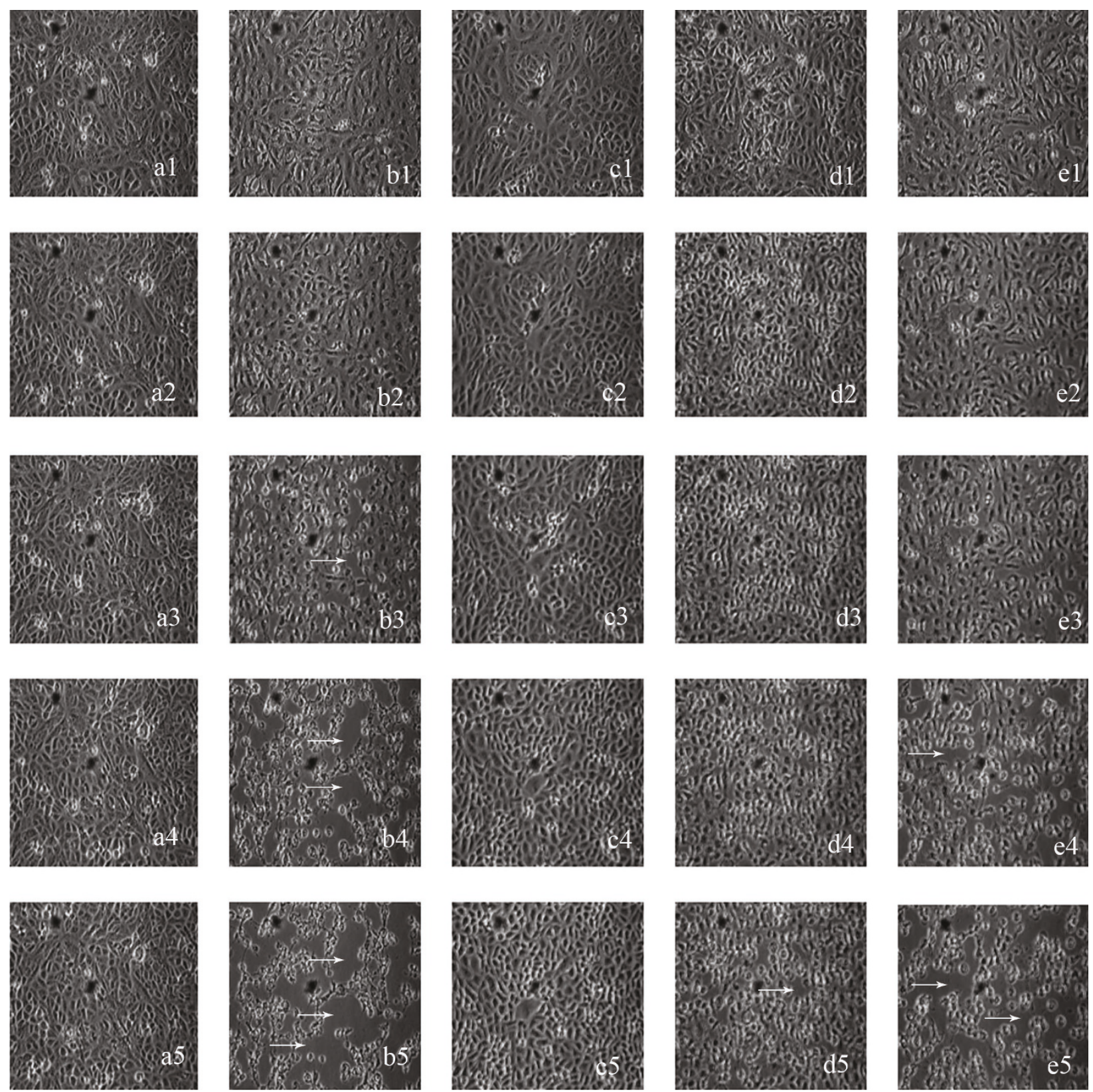

Figure 3 Effect of VR1 CFS in delaying the cytotoxicity caused by A. veronii. Time lapse microscopic studies were carried out until $10 \mathrm{~h}$ incubation of Vero cells with different treatments of culture supernatant of $A$. veronii and VR1 in 1:10 ratio. We show here the representative images from the treatment of a) control b) A. veronii c) VR1 d) pre-incubation of VR1 for $6 \mathrm{~h}$ and then addition of $A$. veronii e) co-incubation of VR1 and $A$. veronii. Images a1-a5 represents the incubation time of 2, 4, 6, 8 and $10 \mathrm{~h}$, respectively. Same denomination is followed for other treatments as well. Detachment of Vero cells can be observed from $6 \mathrm{~h}$ onwards in A. veronii treated cells. Arrow indicates cell detachment.

similar effects, we studied the time dependent effects of CFS of $A$. veronii, VR1, in combination or treatment of A. veronii on VR1 pre-incubated cells. We found that pre-incubation of Vero cells with VR1 CFS delayed cytotoxicity, which was induced by $A$. veronii. Vacuolating cytotoxic factor from $A$. veronii was earlier reported to cause cell death [38].
Tight junction disruption is considered to be one of the indicators of morphological damage caused due to cytotoxicity. MDCK cell line infected with $V$. cholerae cytotoxin and S. typhimurium showed a clear indication of epithelial barrier dysfunction by disruption of tight junction $[39,40]$. In fish, pre-incubation with prospective probiont L. delbrueckii sub sp. lactis could prevent 

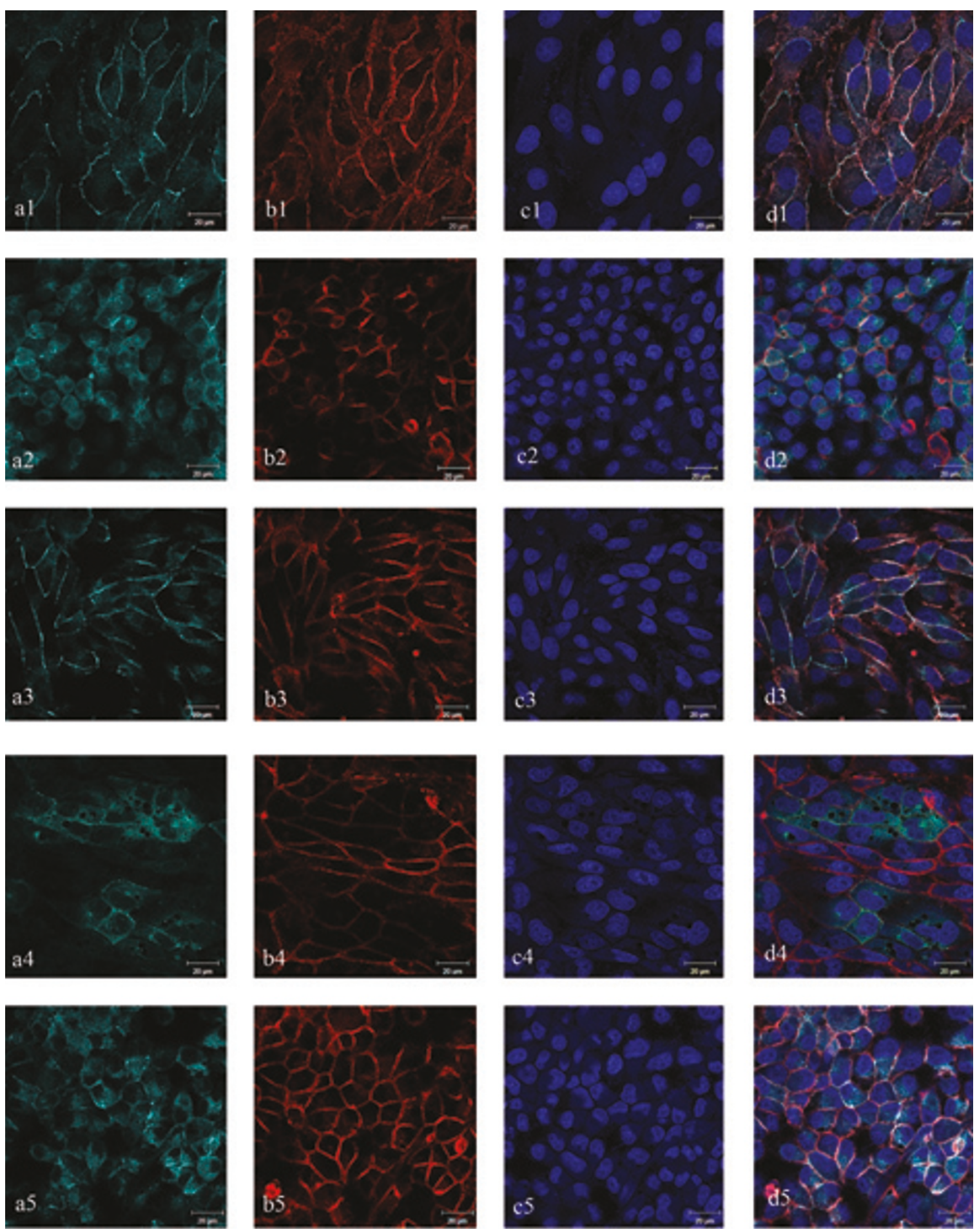

Figure 4 Prevention of membrane damage caused due to A. veronii by pre-incubated with CFS of VR1. Epithelial damage observed by immunofluorescence of tight junction proteins ZO-1 and F-actin in MDCK cell line. a) ZO-1 b) Actin c) DAPI d) Merged images for different

treatment groups: 1) control, 2) A. veronii 3) VR1 4) co-incubation of VR1 with A. veronii 5) pre-incubation of VR1 with A. veronii. Pre-incubation of VR1 prevents epithelial damage due to $A$. veronii as observed in the merged image. Scale denotes $20 \mu \mathrm{m}$ in all images. 


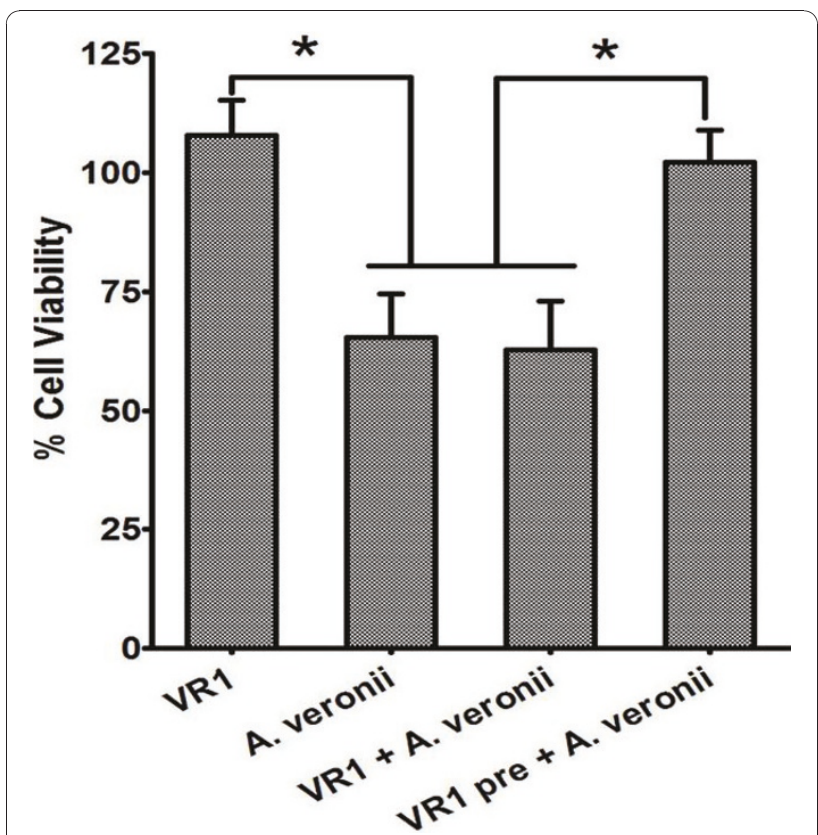

Figure 5 Effect of VR1 culture supernatant in preventing the loss of cell viability caused due to $A$. veronii. MTT assay was performed to quantify percentage cell viability with treatment of supernatant of $A$. veronii and VR1, in 1:10 ratio. Cell viability graph demonstrates that the pre-incubation with VR1 supernatant for $6 \mathrm{~h}$ significantly increased the cell viability. Statistical significance was determined by two tailed student's $t$-test $\left(n=3 \pm\right.$ SEM, $\left.{ }^{*} p<0.05\right)$.

epithelial damage caused by A. salmonicida [36]. To investigate the effect of CFS derived from VR1, and $A$. veronii on epithelial barrier, we selected MDCK cell line over Caco2 cell line because it exhibits similar epithelial characteristics like formation of uniform columnar epithelia, tight junction, and it has an advantage of a short culture period of 5-7 days in comparison to Caco2 which has 21 days of growth period [41-43]. We found that $A$. veronii indeed caused epithelial damage by disruption of ZO-1 and F-Actin in MDCK cell line, which was prevented by pre-incubation with VR1 supernatant for $6 \mathrm{~h}$, whereas co-incubation was not able to restore the epithelial integrity. ZO-1 is a cytoplasmic protein which interacts directly with F-Actin and is very important in structural and functional organisation of tight junction. In this study, microscopic observation of cellular damage is well supported by immunolocalization of ZO-1 and F-Actin, which give clear evidence of VR1 in ameliorating the epithelial damage caused by $A$. veronii. This finding is consistent with earlier report that, $L$. rhamnosus GG treatment ameliorated the redistribution of ZO-1 and claudin in MDCK cell line caused by enterohemorrhagic E. coli [16]. In another study, incubation with CFS of B. lactis 420 has been shown to increase the intestinal epithelial integrity against enteropathogenic E. coli (EPEC) [44].
Cell viability assessed by MTT assay revealed that VR1 CFS treatment was not detrimental to cells and there was no loss in viability when pre-incubated with VR1 CFS. On the other hand, co-incubation could not prevent the loss in cell viability caused by $A$. veronii. Preincubation of Caco2 with p40 and p75 isolated from the soluble protein of L. rhamnosus GG, abrogated the disruptive effect of $\mathrm{H}_{2} \mathrm{O}_{2}$ on tight junctions of Caco2 cells [45]. The protective effect of soluble proteins was shown to be by activation of MAP kinase and PKC dependent signalling pathways. One more study (Parassol et al., [46]) documented that pre-incubation of $L$. casei with T84 cells could abolish the invasion and adhesion of EPEC. On these lines, we speculate, pre-incubation of mammalian cells with CFS of Lactobacilli sp. initiates cellular signalling which either inhibits or upregulate tight junction proteins that may get damaged by entero pathogens.

In view of the increasing prevalence of Aeromonas spp. in food products, this study assumes significance of its application of $L$. plantarum as a potential probiotic microorganism. The findings also suggest that the regular usage of probiotic microorganisms in food preparations can prevent the cytotoxicity or manifestation of pathogenicity in future encounter with pathogens. Further in depth studies will be necessary to understand the preventive role of VR1 in invivo model for A. veronii infection and to identify its active component which may be used as potential preventive cure against gastrointestinal infection.

\section{Conclusions}

To the best of our knowledge, this is the first report of isolation of potential probiotic isolate, L. plantarum VR1 from Kutajarista, an ayurvedic fermented medicine. CFS of VR1 possesses strong antibacterial property against $A$. veronii and reduces its cytotoxic effects in MDCK and Vero cell lines. Hence, L. plantarum can be an effective probiotic to prevent Aeromonas infection as well, as it has been proposed for some other enteric pathogens.

\section{Methods}

\section{Bacterial strains and growth conditions}

for mammalian cells

The bacterial strains used in this study are $A$. veronii MTCC 3249, L. plantarum (VR1) NCIM 5395 and $E$. coli DH5 $\alpha$. Strains used for antimicrobial study were $S$. aureus (ATCC 6538P), Sarcina lutea (ATCC 9341), E. coli (ATCC 8739), P. aeruginosa (ATCC 27853), S. epidermidis (ATCC 12228), clinical isolates of $P$. aeruginosa (DMH 1), E. coli (DMH 9). All the above mentioned type strains, $A$. veronii and $E$. coli were maintained in Luria Bertani (LB) medium at $37^{\circ} \mathrm{C}$. VR1 was 
grown in Man Rogosa Sharpe (MRS) medium (Himedia Laboratories, Mumbai, India) at $37^{\circ} \mathrm{C}$. Overnight grown cultures of $A$. veronii and VR1 were inoculated into 5 $\mathrm{ml}$ of LB and MRS medium respectively, at $37^{\circ} \mathrm{C}$ with shaking at $200 \mathrm{rev} \mathrm{min}^{-1}$. Cell-free supernatant was prepared by centrifugation $\left(10,000 \mathrm{~g}\right.$ for $2 \mathrm{~min}$ at $\left.4^{\circ} \mathrm{C}\right)$ followed by filtration of the supernatants through a 0.22 $\mu \mathrm{m}$ pore size membrane filter (Millipore, India). The filtrates were either refrigerated before use or used immediately. HT-29 (Human colon adenocarcinoma), Vero (African green monkey Kidney) and MDCK (MadinDarby Canine Kidney) epithelial cell lines, were purchased from the animal cell repository of National Centre for Cell Science, India and maintained in DMEM supplemented with $10 \%$ Fetal Calf serum and $1 \times$ Penicillin-streptomycin (Invitrogen, Carlsbad CA).

\section{Isolation and identification of Lactobacillus spp. from Kutajarista}

Several samples of Kutajarista, (an Ayurvedic fermented decoction) were taken at initial days of fermentation. A number of lactic acid bacterial strains were isolated (serial dilution with saline) in MRS plate and incubated at $37^{\circ} \mathrm{C}$ for $2-3$ days. All isolated strains were subsequently propagated in MRS broth and were stored in $40 \%$ glycerol in $-80^{\circ} \mathrm{C}$. Molecular identification was carried out by amplification and sequencing of $\sim 1.5 \mathrm{~Kb}$ partial sequence of $16 \mathrm{~S}$ rRNA gene by using Eubacteria specific 16F27 (5'-CCA GAG TTT GAT CMT GGC TCA G-3') and 16R1488 (5'- CGG TTA CCT TGT TAC GAC TTC ACC -3') [23]. The 16S rRNA gene sequence for the strain VR1 was submitted to Genbank with accession number HQ328838. VR1 showed 99\% homology with Lactobacillus plantarum and its phylogenetic affiliation was deduced by neighbour joining method in MEGA 4.0.

\section{In vitro characterisation of VR1 for probiotic attributes}

MRS broth was used to simulate the acidic condition of intestine by adjusting the $\mathrm{pH}$ of the broth to $\mathrm{pH} 2$. For bile tolerance test, MRS broth was supplemented with $0.3 \%$ bile salts (Oxgall, Himedia, India). Simulated intestinal fluid was prepared to assess passage through the upper gastrointestinal tract. The composition of simulated gastric juice was $1.28 \mathrm{~g} \mathrm{NaCl}, 0.239 \mathrm{~g} \mathrm{KCl}, 6.4$ g $\mathrm{NaHCO}_{3}, 0.3 \%$ bile salts, $0.1 \%(\mathrm{w} / \mathrm{v})$ pancreatin ( $\mathrm{Hi}$ media Labs) per litre of distilled water and the $\mathrm{pH}$ to 7.5 adjusted by adding $\mathrm{HCl}$ [30]. For all the tolerance tests, $5 \mathrm{ml}$ overnight grown Lactobacillus strains were collected by centrifugation and washed twice with $4 \mathrm{ml}$ of PBS and inoculated (at $10^{9} \mathrm{CFU} / \mathrm{ml}$ ) in MRS broth with modifications for acid, bile and gastric juice tolerance medium mentioned above. Then the number of viable VR1 cells was determined by serial dilution and plate-count method.

\section{Antimicrobial activity of VR1}

The antimicrobial activity of VR1 was determined by well diffusion assay as described by Chiu et al. [47]. Bacterial strains included in this study were $S$. aureus (ATCC 6538P), S. lutea (ATCC 9341), A. veronii (MTCC 3249), E. coli (ATCC 8739), P. aeruginosa (ATCC 27853), S. epidermidis (ATCC 12228), and clinical isolates $P$. aeruginosa (DMH 1), and E. coli (DMH 9). These bacterial isolates were grown overnight in LB broth and further diluted to $10^{7} \mathrm{CFU} / \mathrm{mL}$ and spread on LB agar plates. One hundred microliters of filtered spent CFS of VR1 were pipetted into the well on nutrient agar and then plates were incubated at $37^{\circ} \mathrm{C}$ for 12 $14 \mathrm{~h}$. The diameters of the zone of inhibition were measured.

\section{Adhesion assay of VR1}

Adhesion of VR1 was performed using HT-29 cells as described earlier with little modification $[2,4]$. Briefly, monolayers of HT-29 were used at the late confluence with change of media every 2 days. HT-29 monolayers were washed twice with sterile PBS. The Antibiotic free media was added to each well and incubated for $12 \mathrm{~h}$. For each adhesion assay, $1 \mathrm{ml}$ of VR1 suspension (the final concentration of bacteria was $10^{9} \mathrm{CFU} / \mathrm{ml}$ ) was mixed with $1 \mathrm{ml}$ of DMEM and added to different wells. The plates were incubated at $37^{\circ} \mathrm{C}$ for $1.5 \mathrm{~h}$ in the presence of $5 \% \mathrm{CO}_{2}$. After incubation, monolayer was washed with sterile PBS. One $\mathrm{ml}$ of $0.2 \%$ trypsin was added to each well and incubated for $15 \mathrm{~min}$ at Room temperature (RT). The cell suspension was plated on MRS agar by serial dilution using saline. Results were interpreted as percentage adhesion, the ratio between adherent bacteria and added bacteria per well. Three independent experiments were carried out in duplicate.

\section{DNA manipulations, Hybridization, PCR and Sequencing}

$A$. veronii genomic DNA was extracted using a standard method [48]. Primer pairs and PCR conditions used for amplification of aerolysin, hemolysin and asc $V$ genes are given in additional file 3, Table S1. Dot blot hybridization was performed with ${ }^{\alpha 32} \mathrm{P}$ labelled dATP using Amersham Megaprime DNA labelling system. Transfer of DNA to nylon membrane, hybridization conditions, and visualization were according to the manufacturer's protocol. DNA sequencing was carried out on 3730 DNA Analyzer with an ABI PRISM BigDye Terminator cycle sequencing kit (Applied Biosystems). The partial sequence of $A$. veronii asc $V$ gene was submitted to Genbank with accession number HQ602648. 


\section{Assessment of vacuole formation by light microscopy}

Bacterial cultures were grown and CFS was prepared as described above and processed for vacuolation assay as described previously $[33,49]$ with slight modifications. Briefly, Vero cells were seeded in six well tissue culture plate with cell density of $1 \times 10^{5}$ cells $/ \mathrm{ml}$. The cells were allowed to settle, attach and grow for $24 \mathrm{~h}$ prior to use. $100 \mu \mathrm{l}$ of filter sterilized $A$. veronii, and VR1 CFS, were added to the respective wells, mixed gently and incubated for $5 \mathrm{~h}$ before taking the images. One of the wells was pre-incubated with VR1 supernatant for $6 \mathrm{~h}$ before the addition of $A$. veronii supernatant. Vacuolation was observed by Phase contrast microscopy (Nikon 2000, Japan). Images were taken under $20 \times$ objective and were analysed using image pro software (Media Cybernetics, Inc, Bethesda, MD).

\section{Time lapse microscopic analysis of cytotoxic effect}

For photomicroscopy, Vero cells were seeded in six well tissue culture plate with the density of $1 \times 10^{5}$ cells/ well. After $24 \mathrm{~h}$ of incubation for cell attachment, cells were treated with bacterial supernatant with a concentration of 1:10 to the culture media; one of the wells was pre-incubated with probiotic supernatant for $6 \mathrm{~h}$ prior to the treatment with $A$. veronii supernatant. Other treatment groups were same as described above. Live imaging was performed and images were captured at the intervals of 30 min using NIKON TE 2000 under $20 \times$ objective. Images were analysed by Image pro from media analytica.

\section{Analysis of ZO-1 and F-actin distribution by confocal microscopy}

MDCK cells were seeded on the cover slips into 24 well tissue culture plates and incubated with 1:10 ratio of CFS of $A$. veronii and VR1. The tissue-culture plates were incubated in $5 \% \mathrm{CO}_{2}$ atmosphere at $37^{\circ} \mathrm{C}$ for $10 \mathrm{~h}$ with $A$. veronii supernatant, or with VR1, in other group three wells were pre-incubated with VR1 for 6 h before addition of $A$. veronii supernatant. The immunofluorescence staining protocol was adopted from Johnson-Henry, [16]. Briefly, MDCK cell monolayers were rinsed with PBS, followed by fixation and permeabilization with $0.1 \%$ triton X-100 for 5 min at RT. Cells were incubated in $5 \%$ (vol/vol) bovine serum in PBS for $1 \mathrm{~h}$ at RT and then incubated with primary mouse anti-ZO-1 (339100, Invitrogen, molecular probes, USA) for $1 \mathrm{~h}$. Unbound primary antibodies were rinsed and removed by washes with PBS, cells were incubated with secondary ALEXAfluor 633 goat anti-mouse IgG (1:50 dilution; Molecular Probes) and Rhodaminephalloidin (1: 100 dilution, R-415, Molecular probes) for 1 $\mathrm{h}$ at RT. Host cell nuclei were counterstained with 300 nM 4',6-diamidino-2-phenylindole dilactate (DAPI) (Molecular Probes) in PBS for $5 \mathrm{~min}$. Monolayers were thoroughly rinsed with PBS, mounted on slides and examined under confocal laser scanning microscope at $1-\mu \mathrm{m}$ intervals (Zeiss LSM510; Zeiss, Germany).

\section{Cytotoxicity assay}

MTT reduction assay was performed to determine the effect of CFS of $A$. veronii on Vero cell viability. This method was adopted from Couto et al. [50] with little modifications. $10 \mu \mathrm{l}$ of CFS of VR1 and A. veronii were added to a final concentration of 1: 10 in culture media of Vero cells cultivated in 96-well tissue culture plates. The tissue-culture plates were incubated in $5 \% \mathrm{CO}_{2}$ atmosphere at $37^{\circ} \mathrm{C}$ for $10 \mathrm{~h}$. Monolayers was examined after $10 \mathrm{~h}$ of incubation for cytotoxic effect. $20 \mu \mathrm{l}$ of MTT solution (5 $\mathrm{mg} \mathrm{ml}^{-1}$ ) was added to every well. After incubation for $3 \mathrm{~h}$ at $37^{\circ} \mathrm{C}$, the media was removed and precipitated formazan was dissolved with $100 \mu \mathrm{l}$ of DMSO. The absorbance was measured at 570 $\mathrm{nm}$ using Micro-plate reader (Multiskan Ascent V1.24). The cell viability was expressed as the mean of percentages of treated and untreated monolayers. Experiments were performed in triplicate.

\section{Additional material}

Additional file 1: Figure S1. Phylogenetic relationships of VR1 to reference strains of the genus Lactobacillus. The unrooted phylogenetic tree was drawn using 1320 nucleotides of $16 \mathrm{~S}$ rRNA gene sequence using the neighbour-joining method in MEGA software. The bar represents distance values calculated in MEGA and values at nodes represent bootstrap percentages. Bootstrap values less than $50 \%$ is not shown

Additional file 2: Figure S2. Detection of Hemolysin and Aerolysin genes in $\boldsymbol{A}$. veronii. (A) Dot Blot of genomic DNA with Hemolysin gene as a probe. Lane 1- A. hydrophila ATCC 3484; Lane 2- A. hydrophila ATCC 7966; Lane 3- A. veronii (B) Lane 1, A. veronii aerolysin partial gene; Mmolecular weight marker (Invitrogen). (C) Lane 1, A. veronii haemolysin partial gene; Lane 2, A. hydrophila ATCC 3484; Lane 3, A. hydrophila ATCC 7966, M- molecular weight marker (Invitrogen).

Additional file 3: Table S1. Primer combinations used for detecting the virulence gene determinants in $A$. Veronii. Primer pairs used for amplification of aerolysin, hemolysin and ascV genes.

\section{Acknowledgements}

We thank Prof. V.V. Doiphode; Pune University for procuring the ayurvedic fermented medicines. We also thank Mandar Rasane, National Centre for Cell Science, Pune for help with acid and bile tolerance experiments. We thank CSIR (Council of Scientific and Industrial Research) and DBT (Department of Biotechnology) India for providing research fellowship to Himanshu Kumar. We thank Dr. Padma Shastry, National Centre for Cell Science, for critical reading of the manuscript and suggestions.

\section{Author details}

${ }^{1}$ Molecular Biology Unit, National Centre for Cell Science, Ganeshkhind, Pune Maharashtra, India. ${ }^{2}$ Department of Pharmacy and Medicine, University of Picardie Jules Verne, Rue des Louvels, F-80037, Amiens, France. ${ }^{3}$ Department of Chemical and Biological Engineering, State University of New York at Buffalo, Buffalo NY 14260, USA. ${ }^{4}$ Microbial Culture Collection, Hindustan Antibiotics Ltd. Complex, Pimpri, Pune 411 018, Maharashtra, India. 


\section{Authors' contributions}

HK, AYR, YSS and MSP designed this study. HK and AYR were involved in standardization of the experimental conditions. HK was involved in acquisition of the data. HK, AYR, KMD and ANA analyzed and interpreted the data. HK wrote the first draft of the manuscript, other authors edited and revised the manuscript. All authors read and approved the final manuscript.

\section{Competing interests}

The authors declare that they have no competing interests.

Received: 6 April 2011 Accepted: 27 June 2011 Published: 27 June 2011

\section{References}

1. Gaudana SB, Dhanani AS, Bagchi T: Probiotic attributes of Lactobacillus strains isolated from food and of human origin. Br J Nutr 103(11):1620-1628.

2. Kaushik JK, Kumar A, Duary RK, Mohanty AK, Grover S, Batish VK: Functional and probiotic attributes of an indigenous isolate of Lactobacillus plantarum. PLoS One 2009, 4(12):e8099.

3. Patel AK, Ahire JJ, Pawar SP, Chaudhari BL, Chincholkar SB: Comparative accounts of probiotic characteristics of Bacillus spp. isolated from food wastes. Food Research International 2009, 42(4):505-510

4. Lim SM, Im DS: Screening and characterization of probiotic lactic acid bacteria isolated from Korean fermented foods. J Microbiol Biotechnol 2009, 19(2):178-186.

5. Satish Kumar R, Ragu Varman D, Kanmani P, Yuvaraj N, Paari K, Pattukumar V, Arul V: Isolation, Characterization and Identification of a Potential Probiont from South Indian Fermented Foods and Its Use as Biopreservative. Probiotics and Antimicrobial Proteins 2(3):145-151.

6. Reddy KB, Raghavendra P, Kumar BG, Misra MC, Prapulla SG: Screening of probiotic properties of lactic acid bacteria isolated from Kanjika, an ayruvedic lactic acid fermented product: an in-vitro evaluation. J Gen Appl Microbiol 2007, 53(3):207-213.

7. Garg S, Bhutani KK: Chromatographic analysis of Kutajarista-an ayurvedic polyherbal formulation. Phytochem Anal 2008, 19(4):323-328.

8. Sekar SMS: Traditionally fermented biomedicines, arishtas and asavas from Ayurveda. Indian Journal of Traditional Knowledge 2008, 7(4):548-556

9. Hugo AA, Kakisu E, De Antoni GL, Perez PF: Lactobacilli antagonize biological effects of enterohaemorrhagic Escherichia coli in vitro. Lett Appl Microbiol 2008, 46(6):613-619.

10. Qin $H$, Zhang $Z$, Hang $X$, Jiang $Y$ : L. plantarum prevents enteroinvasive Escherichia coli-induced tight junction proteins changes in intestinal epithelial cells. BMC Microbiol 2009, 9:63.

11. Ryan KA, O'Hara AM, van Pijkeren JP, Douillard FP, O'Toole PW: Lactobacillus salivarius modulates cytokine induction and virulence factor gene expression in Helicobacter pylori. J Med Microbiol 2009, 58(Pt 8):996-1005

12. Hudault S, Lievin V, Bernet-Camard MF, Servin AL: Antagonistic activity exerted in vitro and in vivo by Lactobacillus casei (strain $\mathrm{GG}$ ) against Salmonella typhimurium C5 infection. Appl Environ Microbiol 1997, 63(2):513-518.

13. Moorthy G, Murali MR, Devaraj SN: Lactobacilli facilitate maintenance of intestinal membrane integrity during Shigella dysenteriae 1 infection in rats. Nutrition 2009, 25(3):350-358.

14. Sanchez B, Urdaci M, Margolles A: Extracellular proteins secreted by probiotic bacteria as mediators of effects that promote mucosal-bacteria interactions. Microbiology 2010, 156:3232-3242.

15. Ewaschuk JB, Diaz H, Meddings L, Diederichs B, Dmytrash A, Backer J, Looijer-van Langen M, Madsen KL: Secreted bioactive factors from Bifidobacterium infantis enhance epithelial cell barrier function. Am J Physiol Gastrointest Liver Physiol 2008, 295(5):G1025-1034.

16. Johnson-Henry KC, Donato KA, Shen-Tu G, Gordanpour M, Sherman PM: Lactobacillus rhamnosus strain GG prevents enterohemorrhagic Escherichia coli 0157:H7-induced changes in epithelial barrier function. Infect Immun 2008, 76(4):1340-1348.

17. Anderson RC, Cookson AL, McNabb WC, Park Z, McCann MJ, Kelly WJ, Roy NC: Lactobacillus plantarum MB452 enhances the function of the intestinal barrier by increasing the expression levels of genes involved in tight junction formation. BMC Microbiol 10:316.

18. Roselli M, Finamore A, Britti MS, Konstantinov SR, Smidt H, de Vos WM, Mengheri E: The novel porcine Lactobacillus sobrius strain protects intestinal cells from enterotoxigenic Escherichia coli K88 infection and prevents membrane barrier damage. J Nutr 2007, 137(12):2709-2716.

19. Kannan S, Chattopadhyay UK, Pal D, Shimada T, Takeda Y, Bhattacharya SK, Ananthanarayanan PH: Isolation and identification of Aeromonas from patients with acute diarrhoea in Kolkata, India. Indian J Med Microbiol 2001, 19(4):190-192.

20. Bhowmik P, Bag PK, Hajra TK, De R, Sarkar P, Ramamurthy T: Pathogenic potential of Aeromonas hydrophila isolated from surface waters in Kolkata, India. J Med Microbiol 2009, 58(Pt 12):1549-1558.

21. Soltan Dallal MM, Moezardalan K: Aeromonas spp associated with children's diarrhoea in Tehran: a case-control study. Ann Trop Paediatr 2004, 24(1):45-51.

22. Janda JM, Abbott SL: The genus Aeromonas: taxonomy, pathogenicity, and infection. Clin Microbiol Rev 23(1):35-73.

23. Pidiyar V, Kaznowski A, Narayan NB, Patole M, Shouche YS: Aeromonas culicicola sp. nov., from the midgut of Culex quinquefasciatus. Int I Syst Evol Microbiol 2002, 52(Pt 5):1723-1728.

24. Handfield M, Simard P, Couillard M, Letarte R: Aeromonas hydrophila isolated from food and drinking water: hemagglutination, hemolysis, and cytotoxicity for a human intestinal cell line (HT-29). Appl Environ Microbiol 1996, 62(9):3459-3461.

25. Figueras MJ, Suarez-Franquet A, Chacon MR, Soler L, Navarro M, Alejandre C, Grasa B, Martinez-Murcia AJ, Guarro J: First record of the rare species Aeromonas culicicola from a drinking water supply. Appl Environ Microbiol 2005, 71(1):538-541.

26. Pidiyar VJ, Jangid K, Dayananda KM, Kaznowski A, Gonzalez JM, Patole MS, Shouche YS: Phylogenetic affiliation of Aeromonas culicicola MTCC 3249 (T) based on gyrB gene sequence and PCR-amplicon sequence analysis of cytolytic enterotoxin gene. Syst Appl Microbiol 2003, 26(2):197-202.

27. Jangid K, Kong R, Patole MS, Shouche YS: luxRI homologs are universally present in the genus Aeromonas. BMC Microbiol 2007, 7:93.

28. Rangrez AY, Dayananda KM, Atanur S, Joshi R, Patole MS, Shouche YS: Detection of conjugation related type four secretion machinery in Aeromonas culicicola. PLoS One 2006, 1:e115.

29. Rangrez AY, Abajy MY, Keller W, Shouche Y, Grohmann E: Biochemical characterization of three putative ATPases from a new type IV secretion system of Aeromonas veronii plasmid pAC3249A. BMC Biochem 11:10.

30. Pennacchia C, Blaiotta G, Pepe O, Villani F: Isolation of Saccharomyces cerevisiae strains from different food matrices and their preliminary selection for a potential use as probiotics. J Appl Microbiol 2008, 105(6):1919-1928.

31. Tuomola EM, Salminen SJ: Adhesion of some probiotic and dairy Lactobacillus strains to Caco-2 cell cultures. Int J Food Microbiol 1998, 41(1):45-51.

32. Ghatak S, Agarwal RK, Bhilegaonkar KN: Comparative study of cytotoxicity of Aeromonas spp. on four different cell lines. Comp Immunol Microbiol Infect Dis 2006, 29(4):233-241.

33. Di Pietro A, Picerno I, Visalli G, Chirico C, Spataro P, Cannavo G, Scoglio ME: Aeromonas hydrophila exotoxin induces cytoplasmic vacuolation and cell death in VERO cells. New Microbiol 2005, 28(3):251-259.

34. Balaji V, Jesudason MV, Sridharan G: Cytotoxin testing of environmental Aeromonas spp. in Vero cell culture. Indian J Med Res 2004, 119(5):186-189.

35. Balcazar JL, Vendrell D, de Blas I, Ruiz-Zarzuela I, Muzquiz JL: Effect of Lactococcus lactis CLFP 100 and Leuconostoc mesenteroides CLFP 196 on Aeromonas salmonicida Infection in brown trout (Salmo trutta). J Mol Microbiol Biotechnol 2009, 17(3):153-157.

36. Salinas I, Myklebust R, Esteban MA, Olsen RE, Meseguer J, Ringo E: In vitro studies of Lactobacillus delbrueckii subsp. lactis in Atlantic salmon (Salmo salar L.) foregut: tissue responses and evidence of protection against Aeromonas salmonicida subsp. salmonicida epithelial damage. Vet Microbiol 2008, 128(1-2):167-177.

37. Anderson RC, Cookson AL, McNabb WC, Kelly WJ, Roy NC: Lactobacillus plantarum DSM 2648 is a potential probiotic that enhances intestinal barrier function. FEMS Microbiol Lett 309(2):184-192.

38. Martins LM, Catani CF, Falcon RM, Carbonell GV, Azzoni AA, Yano T: Induction of apoptosis in Vero cells by Aeromonas veronii biovar sobria vacuolating cytotoxic factor. FEMS Immunol Med Microbiol 2007, 49(2):197-204. 
39. Wu Z, Nybom P, Magnusson KE: Distinct effects of Vibrio cholerae haemagglutinin/protease on the structure and localization of the tight junction-associated proteins occludin and ZO-1. Cell Microbiol 2000, 2(1):11-17.

40. Jepson MA, Schlecht HB, Collares-Buzato CB: Localization of dysfunctional tight junctions in Salmonella enterica serovar typhimurium-infected epithelial layers. Infect Immun 2000, 68(12):7202-7208.

41. Le Ferrec E, Chesne C, Artusson P, Brayden D, Fabre G, Gires P, Guillou F, Rousset M, Rubas W, Scarino ML: In vitro models of the intestinal barrier. The report and recommendations of ECVAM Workshop 46. European Centre for the Validation of Alternative methods. Altern Lab Anim 2001, 29(6):649-668.

42. Irvine JD, Takahashi L, Lockhart K, Cheong J, Tolan JW, Selick HE, Grove JR: MDCK (Madin-Darby canine kidney) cells: A tool for membrane permeability screening. J Pharm Sci 1999, 88(1):28-33.

43. Balimane PV, Chong S, Patel K, Quan Y, Timoszyk J, Han YH, Wang B, Vig B, Faria TN: Peptide transporter substrate identification during permeability screening in drug discovery: comparison of transfected MDCK-hPepT1 cells to Caco-2 cells. Arch Pharm Res 2007, 30(4):507-518.

44. Putaala H, Salusjarvi T, Nordstrom M, Saarinen M, Ouwehand AC, Bech Hansen E, Rautonen N: Effect of four probiotic strains and Escherichia coli 0157:H7 on tight junction integrity and cyclo-oxygenase expression. Res Microbiol 2008, 159(9-10):692-698.

45. Seth A, Yan F, Polk DB, Rao RK: Probiotics ameliorate the hydrogen peroxide-induced epithelial barrier disruption by a PKC- and MAP kinase-dependent mechanism. Am J Physiol Gastrointest Liver Physiol 2008, 294(4):G1060-1069

46. Parassol N, Freitas M, Thoreux K, Dalmasso G, Bourdet-Sicard R, Rampal P: Lactobacillus casei DN-114 001 inhibits the increase in paracellular permeability of enteropathogenic Escherichia coli-infected T84 cells. Res Microbiol 2005, 156(2):256-262.

47. Chiu HH, Tsai CC, Hsih HY, Tsen HY: Screening from pickled vegetables the potential probiotic strains of lactic acid bacteria able to inhibit the Salmonella invasion in mice. J Appl Microbiol 2008, 104(2):605-612.

48. Sambrook J, Fritsch EF, Maniatis T, (ed): Molecular cloning: a laboratory manual. Cold Spring Harbor Laboratory Press; 21989.

49. Figueroa-Arredondo P, Heuser JE, Akopyants NS, Morisaki JH, GionoCerezo S, Enriquez-Rincon F, Berg DE: Cell vacuolation caused by Vibrio cholerae hemolysin. Infect Immun 2001, 69(3):1613-1624.

50. Couto CR, Oliveira SS, Queiroz ML, Freitas-Almeida AC: Interactions of clinical and environmental Aeromonas isolates with Caco-2 and HT29 intestinal epithelial cells. Lett Appl Microbiol 2007, 45(4):405-410.

doi:10.1186/1471-2180-11-152

Cite this article as: Kumar et al:. Lactobacillus plantarum (VR1) isolated from an Ayurvedic medicine (Kutajarista) ameliorates in vitro cellular damage caused by Aeromonas veronii. BMC Microbiology 2011 11:152.

\section{Submit your next manuscript to BioMed Central and take full advantage of:}

- Convenient online submission

- Thorough peer review

- No space constraints or color figure charges

- Immediate publication on acceptance

- Inclusion in PubMed, CAS, Scopus and Google Scholar

- Research which is freely available for redistribution 